\title{
A Study of Motivational Factors, Incentive Preferences, and Unpleasant Events during Blood Donation among Blood Donors
}

\author{
Deepa Narayanan ${ }^{1}$, Archana Rajan² \\ 1, 2 Department of Transfusion Medicine, Government Medical Collage, Kozhikode, Kerala, India.
}

\section{ABSTRACT}

\section{BACKGROUND}

Timely access to safe blood is necessary for the functioning of all hospitals. Low donation rate was said to be one of the difficulties in providing safe blood to patients. Donors mostly donated blood when they were asked to donate blood by others. Some blood donors are reluctant to donate blood because of some uncomfortable experiences. Knowing motivational factors in our region will help us in increasing blood donation. Blood donation can also be increased by trying to reduce the uncomfortable experiences of blood donors during blood donation and finding solutions to the barriers of blood donation. Incentives can also help in increasing blood donation. We wanted to study the motivational factors, unpleasant events and incentives preferred among blood donors.

\section{METHODS}

This is a cross sectional study conducted in the blood bank at Medical College, Kozhikode in Kerala. Study was done among 1500 consecutive donors who donated blood at Government Medical College, Kozhikode blood bank. Donors who were fit to donate blood were included in the study. The donors were asked to answer the questionnaire. Questions were given in both English and Malayalam. Questionnaire contained questions on motivational factors, unpleasant events, and incentive preferences. Responses were recorded in excel. Statistical analysis was done by SPSS software.

\section{RESULTS}

In our study the most important motivational factor for blood donation was desire to help others in $58.5 \%$ blood donors followed by health benefits of blood donation in $32.1 \%$. The majority of donors reported no unpleasant events in the process of donation (80\%). But long waiting time and long distance of home from the blood bank were barriers for donation in some blood donors. Most of the donors $94.5 \%$ of donors were willing to donate in future. Certificates were the most preferred incentive.

\section{CONCLUSIONS}

Motivational factors like desire to help others and health benefits of blood donation can be used for motivating blood donors. Certificates can be used as an incentive for all donors.

\section{KEY WORDS}

Blood Donation, Blood Donors, Blood Bank
Corresponding Author: Dr. Deepa Narayanan, Kollambalath House Kolathara (P.O), Kozhikode-673655, Kerala, India. E-mail: drdeepa2@gmail.com

DOI: $10.14260 /$ jemds/2020/820

How to Cite This Article:

Narayanan D, Rajan A. A study of motivational factors, incentive preferences and unpleasant events during blood donation among blood donors. J Evolution Med Dent Sci 2020;9(49):3735-3738, DOI: 10.14260/jemds/2020/820

Submission 20-07-2020,

Peer Review 19-10-2020,

Acceptance 26-10-2020,

Published 07-12-2020.

Copyright (C) 2020 Deepa Narayanan et al. This is an open access article distributed under Creative Commons Attribution License [Attribution 4.0 International (CC $B Y 4.0)]$ 


\section{BACKGROUND}

Blood is life saving for many patients; blood also improves the health of many patients. Many patients with chronic anaemia and other blood disorders are able to lead a normal life with the help of blood transfusion. Blood is also needed in many conditions like postpartum haemorrhage, malignancies, and accidents. In paediatric patients' blood is required for care of preterm infants, haemorrhagic disease of new-born and in chronic anaemias like thalassaemia. Timely access of blood is also important in many emergency conditions. Unavailability of blood can lead to increased patient suffering and deaths. In India the need for blood is increasing because of advances in medicine and developments in medical and surgical specialties postpartum haemorrhage is a major cause of maternal death in the country. ${ }^{1}$ Road traffic accidents are also increasing. During the time of disasters also need of blood may be increased. So, maintaining an adequate stock of blood is very important. Blood bank with an adequate stock of blood is very important for the functioning of a hospital.

WHO (World Health Organization) has advocated providing safe blood to patients through 100 percent voluntary donation and 100 percent quality assured testing. ${ }^{2}$ WHO advocates increasing blood donation by understanding of blood donors, educating donors, motivating blood donors and making blood donation a pleasant experience for donors. Low donation rate is said to be one of the difficulties in providing safe blood to patients in many countries. ${ }^{2}$ Blood donation is low in developing countries like India compared to developed countries. India still depends on relative donors when need arises. Many times blood banks do not have enough blood and relatives have to search for blood donors. Voluntary blood donors are very important in providing adequate supplies of blood. Promoting voluntary blood donation also needs support from the government. In India blood banks are under the control of the National blood transfusion council and State blood transfusion council. Different policies are adopted by them for ensuring safe blood supply to the patients. Promotion of voluntary blood donors is most important among them.

Majority of blood donors donated blood when they were asked to donate blood by others. Some people are fearful about blood donation. Finding gaps in motivational factors will help in increasing blood donation. Some people become reluctant to donate because of their past experiences during blood donation like fainting; pain of needle piercing etc. benefits of blood donation on the donor has been highlighted for motivating blood donation. Blood donation improves the emotional wellbeing of blood donors and provides a sense of belonging. There is an increase in demand for blood in Kerala where hospital facilities are available even in rural areas. But finding an adequate number of voluntary donors as per demand is often difficult in hospitals where demand of blood is very high. In blood banks blood required by the patient is donated by both voluntary and replacement donors. Incentives have also been used to promote blood donation in many blood banks. ${ }^{3}$ But the gap in the demand for blood and its supply is still present. Voluntary blood donation has increased in India. The gap between demand and supply can be bridged with proper planning. ${ }^{4}$ National AIDS (Acquired Immune Deficiency Syndrome) control society encourages clubs, colleges, public and private organizations to help in blood donation. It also supports blood banks in various ways to promote voluntary donation. Awards are given to clubs and organizations which promote blood donation. Awards are also given to blood donors who have donated blood many times. Voluntary blood donation helps in getting blood at an affordable cost to all patients. Blood donors may be first time donors or a repeat donor. It is important to motivate a first time donor and retain a blood donor who donates repeatedly to provide patients with quality assured blood.

Many studies have been conducted on motivational factors for blood donation. People donated blood because of altruism, because of a sense of social obligation, recognizing the need for blood, motivation from friends who have donated blood. Incentives are used to motivate blood donors. But care should be taken that incentives do not influence people to donate blood in such a way that quality of blood is affected. So only small incentives like certificates, pens, badges, caps, T shirts, free blood testing are offered to blood donors. Understanding motivational factors will help in increasing the number of voluntary donors coming to the blood bank. Being asked for blood donation and feeling of self-satisfaction, empathetic attitude of staff, considering blood donation as a religious and national duty, are the major motivational factors for blood donation $5,6,7,8,9$

There are many barriers for blood donation like fear, negative attitude towards blood donation, lack of awareness, accessibility problems. ${ }^{10,11,12,13}$ By the activities of NACO (National AIDS Control Organization) and government voluntary blood donation has gradually increased in India. Now many organizations, blood donation groups are taking an active part in blood donation activities. India has a large population so by understanding the motivational factors in blood donation and properly using them can increase the donor pool of the country. India is a country with different cultural backgrounds and so the motivational factors for blood donation may vary from state to state. This study will help us to understand the motivational factors of blood donation of people of Kerala especially of Malabar area. This study aims to find the percentage of different motivational factors among blood donors, to estimate the percentage of donors experiencing different unpleasant events during blood donation, and to estimate percentage of blood donors preferring different incentives.

\section{METHODS}

The study is a cross sectional study conducted in the blood bank at Government Medical College, Kozhikode in Kerala. The study was done after obtaining approval from the Institutional Ethics Committee of Government Medical College Kozhikode. Study was done in 1500 consecutive blood donors who donated blood at Government medical college Kozhikode blood bank. Study was done for a period of one month. The results can be generalised to blood donors. The donors included both voluntary and replacement donors. Donors of age group 18 to 60 . Both males and females who were fit to donate blood after medical examination were included in the study. The donor population came from the Kozhikode district and some came from nearby districts. The donors were asked to answer the questionnaire which was validated by pilot samples. Questionnaire consisted of questions regarding 
factors which motivated donors to donate blood like desire to help others, because of health benefits of blood donation, inspiration from others donating blood or because of compulsion from others to donate blood, unpleasant events and barriers of blood donation like long waiting time, unpleasant behaviour from staff, long distance to travel to blood bank and adverse donor reaction. Whether they will continue to donate in the future and which type of incentives they prefer like certificates, routine blood testing, and other gifts. Those who were not willing to answer the questionnaire were excluded from the study, donors who deferred from blood donation due to various reasons were not included in the study.

\section{Statistical Analysis}

Questions were given in both English and Malayalam, responses were recorded in excel. Descriptive data were presented in the form of frequency and percentages. Statistical analysis was done by SPSS software.

\section{RESULTS}

Table 1. Describes the most important motivational factors of blood donation for blood donors. In our study the most important motivational factor for blood donation was - desire to help others in 877 donors (58.5\%) followed by health benefits of blood donation in 482 donors (32.1\%). Inspiration from others $6.9 \%$. Only 37 donors $(2.5 \%)$ donated due to compulsion from others.

Table 2 shows barriers of donation and unpleasant events during blood donation. The majority of donors reported no unpleasant events in the process of donation 1200 donors $(80$ $\%)$. But long waiting time was reported by 124 donors $(8.26$ $\%)$ long distance from home to the blood bank was a barrier for 101 donors (6.73 percent).

Table 3. Shows donors willing to donate in future, 1418 donors were willing to donate in future (94.5\%). Table 4 . Shows most preferred incentive by blood donors. Certificates were the most preferred incentive by 1309 donor (87.3\%). Blood testing was the most preferred incentive in 183 donors (12.2\%). Other gifts were preferred by 8 donors $(0.5 \%)$ donors.

\begin{tabular}{|ccc|}
\hline Motivational Factor & Number of Donors & Percentage \\
Desire to help others & 877 & 58.5 \\
Health benefits & 482 & 32.1 \\
Inspiration from others & 104 & 6.9 \\
compulsion & 37 & 2.5 \\
\hline Total & $\mathbf{1 5 0 0}$ & \\
\hline Table 1. Motivational Factors for Blood Donation \\
\hline
\end{tabular}

\begin{tabular}{|ccc|}
\hline Unpleasant Events & Number of Donors & Percentage of Donors \\
\hline $\begin{array}{c}\text { No Unpleasant Events / } \\
\text { Barriers }\end{array}$ & 1200 & $80 \%$ \\
Long Waiting Time & 124 & $8.26 \%$ \\
$\begin{array}{c}\text { Unpleasant Behaviour from } \\
\text { Staff }\end{array}$ & 1 & $0.06 \%$ \\
$\begin{array}{c}\text { Long Distance From Home } \\
\text { to Blood Bank }\end{array}$ & 101 & $6.73 \%$ \\
\hline Adverse Donor Reaction & 72 & $4.8 \%$ \\
\hline \multicolumn{2}{|c|}{ Table 2. Unpleasant Events and Barriers of Blood Donation } \\
\hline
\end{tabular}

\begin{tabular}{|ccc|}
\hline & Number of Donors & Percentage \\
\hline Willing to donate in future & 1418 & $94.5 \%$ \\
Not willing to donate in future & 82 & $5.5 \%$ \\
\hline \multicolumn{3}{|c|}{ Table 3. Willingness to Donate in Future } \\
\hline
\end{tabular}

\begin{tabular}{|ccc|}
\hline & Number of Donors & Percentage of Donors \\
\hline Blood Testing & 183 & 12.2 \\
Certificates & 1309 & 87.3 \\
Other Gifts & 8 & 0.5 \\
\hline \multicolumn{3}{|c}{} \\
\hline
\end{tabular}

\section{DISCUSSION}

It is essential to maintain adequate stock of blood and for this adequate blood supply is essential. Understanding the motivational factors of blood donors will help in increasing the blood supply to blood banks. In our country the majority of people who are eligible to become a blood donor have never donated blood, so understanding motivational factors will help us to motivate such people for blood donation. Several studies have been conducted regarding the motivational factors of blood donors. Wanting to help others has been an important motivational factor in many studies; good experience from staff has been a motivational factor for donors. A study conducted by Alisa Zimal etal in college students in Los Angeles showed altruistic and empathetic attitude was a major motivating factor among college students donating blood. ${ }^{6} \mathrm{~A}$ study conducted by Shah et al in Ghana showed that 90.3 percent people donated blood when someone they knew was in need of blood, 83.4 percent of donors considered good attitude of staff as a motivational factor. Desire to help others was a motivational factor for 85.1 percent of donors. ${ }^{7}$ Study by Alfouzan $\mathrm{N}$ showed that blood donation was considered as a religious and national duty. Giving one day off for blood donation and conducting blood donation camp at public places was considered as motivational factors. ${ }^{8}$ Important factors of blood donation for Sub-Saharan Africans were altruism, free health checks and specific recruitment and awareness-raising campaigns. ${ }^{9}$ This study was conducted in 1500 donors who represents donor population of north Kerala showed that desire to help others was the major motivational factor of blood donation, followed by health benefits of blood donation. Majority of donors have a desire to help others so they will donate blood when they are asked again for donating blood. Such donors can increase our repeat donors. Donors were also motivated by health benefits of blood donation so highlighting benefits of blood donation by motivational videos and posters can bring more blood donors.

Some studies have been conducted to know about the factors which act as barriers or causes reluctance to donate blood in donors. Reasons for not donating blood in African American students apart from ineligibility to donate blood due to medical reasons were lack of time, blood donation a painful procedure, fear of blood or seeing a needle. ${ }^{5}$ Fear to donate blood is also a main reason for refusal to donate blood even if importance of blood donation is known.10 Main recurring barriers for Sub-Saharan Africans were low haemoglobin deferral, fear of needles and pain, social exclusion, lack of awareness about blood donation, and accessibility problems. ${ }^{9}$ Lack of awareness about blood donation and accessibility were barriers for blood donation in study by Joshi D in India. ${ }^{11}$ 
Singh AA et al who conducted study in teaching institutions in North India found that barriers to blood donation were fear of needles (29.33\%), inconvenience of blood donation (28.67 $\%$ ), and fear of collapse after donating blood (24.67\%). About $17.33 \%$ were of the view that they might contract the disease in the process of blood donation. $17.33 \%$ cited a reason for not donating blood as lack of time. ${ }^{12}$ In the study by Duba et al in Uttar Pradesh main reason for not donating blood was not being asked to donate blood. Donors also had misconceptions about pain and chances of infection. ${ }^{13}$ In our study most important barriers of donation were long waiting time at the blood bank and long distance of blood bank from home. Thus in our study also donors had accessibility problems like other studies

Many studies have been conducted to know effect of incentives on blood donation. ${ }^{14}$ Incentives were considered in blood donation as altruism alone was not able to meet entire blood requirements. ${ }^{14}$ In the study by Dubey et al certificates were preferred as incentive only in $1.1 \%$ members. ${ }^{13}$ In a study by Glynn et al the attitude of blood donors towards donor incentives were studied. The most preferred incentive was free blood testing like cholesterol testing. While younger donor's preferred incentives like gifts. ${ }^{15}$ The incentives like certificates, gifts and free blood testing were considered in our study as they were more practical in our setting. The most preferred incentive after blood donation in our study was certificates in $87.3 \%$ donors, followed by free blood testing in 12.2 percentage donors. Thus our study showed differences in incentive preferences when compared to other studies.

\section{CONCLUSIONS}

In our study, the most important motivational factor blood donation was the desire to help others followed by health benefits of blood donation. Making people aware that blood donation is a safe procedure and is a simple way to help others will promote blood donation. Creating awareness among blood donors will prevent misconception about blood donations. There may be people who have a desire to help others but have not been approached for blood donation. When people are aware about the need for blood in the hospitals, more donors who have the desire for helping others will come forward for donating blood. Conducting blood donation camps in areas where there are no blood banks will help blood donors who have long distance to travel to reach a blood bank. Certificates can be given as incentives for our donor population as it is the most preferred incentive.

Data sharing statement provided by the authors is available with the full text of this article at jemds.com.

Financial or other competing interests: None.

Disclosure forms provided by the authors are available with the full text of this article at jemds.com.

\section{REFERENCES}

[1] Registrar General of India. Sample registration survey. Maternal mortality in India: 1997-2003, trends, causes and risk factors. New Delhi: Registrar General of India 2006: p. 29.

[2] WHO. Towards 100 percent voluntary blood donation. A global framework for action. 2010.

[3] Kasraian L, Maghsudlu M. Blood donors' attitudes towards incentives: influence on motivation to donate. Blood Transfus 2012;10(2):186-90.

[4] National AIDS Control Organization: Voluntary blood donation program - an operational guideline. New Delhi: Ministry of Health and Family Welfare 2007.

[5] Shaz BH, Demmons DG, Crittenden CP, et al. Motivators and barriers to blood donation in African American College Students. Transfus Apher Sci 2009;41(3):191-7.

[6] Finck R, Ziman A, Hoffman M, et al. Motivating factors and potential deterrents to Blood donation in high school aged Blood donors. J Blood Transfus 2016;2016:8624230.

[7] Mohammed S, Essel HB. Motivational factors for blood donation, potential barriers and knowledge about blood donation in first-time and repeat blood donors. BMC Hematol 2018;18:36.

[8] Alfoun N. Knowledge, attitudes and motivations towards blood donation among King Abdulaziz Medical City population. International Journal of Family Medicine 2014;2014:539670.

[9] Klinkenberg EF, Veld HIEMJ, de Wit PD, et al. Blood donation barriers and facilitators of Sub-Saharan African migrants and minorities in Western high- income countries: a systematic review of the literature. Transfus Med 2019;29(Suppl 1):28-41.

[10] Asmawi U, Osman M, Said N, et al. Barriers for blood donation in non- blood donor: a qualitaive study. Environment - Behaviour Proceedins Journal 2019;4(10).

[11] Joshi D, Meakin R. Views and attitudes towards blood donation: a qualitative investigation of Indian non-donors living in England. BMJ Open 2017;7(10):e018279.

[12] Singh AA, Kaur M, Singh A. An evaluation of barriers to blood donation from a tertiary care teaching institution. J Integr Health Sci 2018;6(1):18-21.

[13] Dubey S, Dua S. A Comparative study between blood donors and the general population in Uttar Pradesh, India, to Analyse the triggers for donation. Annals of Pathology and Laboratory Medicine 2017;4(6):A678-85.

[14] Abolghasemi H, Hosseini-Divkalayi NS, Seighali F. Blood donor incentives: a step forward or backward. Asian J Transfus Sci 2010;4(1):9-13.

[15] Glynn SA, Williams AE, Nass CC, et al. Attitudes toward blood donation incentives in the United States: implications for donor recruitment. Transfus 2003;43(1):7-16. 